\title{
Pior a emenda que o soneto: \\ os reflexos da EC 95/2016
}

\author{
"Pior a emenda que o soneto": \\ the reflexes of Constitutional Amendment 95/2016
}

\section{Peor la enmienda que el soneto:}

los reflejos de la EC 95/2016

\section{PAULO DE SENA MARTINS*}

Câmara dos Deputados, Brasília- DF, Brasil.

\begin{abstract}
RESUMO: O objetivo é discutir a política de austeridade fiscal imposta pelo Governo Federal com a aprovação da Emenda Constitucional nº 95 de 2016 e seus impactos nas políticas sociais, dentre estas, a educação. A análise dos dados orçamentários que informam sobre os gastos públicos da educação demonstram que o Novo Regime Fiscal pode levar à "morte o PNE", retirando-o, inclusive, da agenda política. Se EC 95 tem por objeto a recuperação econômica, infelizmente desconsidera a educação como indutora de outras políticas públicas, como multiplicador do PIB e fator de aumento da produtividade.

Palavras-chave: Emenda Constitucional nº 95. Políticas educacionais. Educação e política de austeridade.
\end{abstract}

\begin{abstract}
The objective is to discuss the tax austerity policy imposed by the Federal Government with the approval of Constitutional Amendment No. 95 of 2016 and its impacts on social policies, and among them, education. The analysis of the budgetary data that report on the public expenses on education demonstrate that the New Tax Regime can lead to the death the PNE (National Plan of Education), even removing it from the political agenda. If Constitutional Amendment (EC95) aims economic recovery, it unfortunately neglects education as an inducer
\end{abstract}

* É doutor em Educação pela Universidade de Brasília. Mestre em Direito Penal pela Universidade de São Paulo. Atua como consultor legislativo da área de Educação, Cultura e Desporto na Câmara dos Deputados. E-mail: <paulo.martins@camara.leg.br>. 
of other public policies, as a multiplier of PIB (GDP - Gross Domestic Product) and productivity increase factor.

Keywords: Constitutional Amendmentn-95. Educational policies. Education and austerity policy.

RESUMEN: El objetivo es discutir la política de austeridad fiscal impuesta por el Gobierno Federal con la aprobación de la Enmienda Constitucional no 95 de 2016 y sus impactos en las políticas sociales, entre ellas, la educación. El análisis de los datos presupuestarios que informan sobre los gastos públicos de la educación demuestra que el Nuevo Régimen Fiscal puede llevar a la "muerte el PNE", retirándolo, inclusive, de la agenda política. Si la EC 95 tiene por objeto la recuperación económica, desafortunadamente desconsidera la educación como inductora de otras políticas públicas, como multiplicador del PIB y factor de aumento de la productividad.

Palabras clave: Enmienda Constitucional no 95. Políticas educacionales. Educación y política de austeridad.

Emenda Constitucional nº 95, de 2016 é a radical expressão normativa da deno-
minada "política de austeridade" cujo objetivo seria enfrentar a crise fiscal. Ela
alterou o Ato das Disposições Constitucionais Transitórias (ADCT), para instituir o Novo Regime Fiscal, cujo núcleo é a imposição, por vinte anos, de limites individualizados para as despesas primárias ${ }^{1}$, em âmbito federal, de órgãos dos poderes Executivo, Legislativo e Judiciário e das funções essenciais à justiça (Ministério Público da União; Conselho Nacional do Ministério Público; Defensoria Pública da União).

Os limites para os exercícios posteriores a $2017^{2}$ equivalem, nos termos do Art. 107, $\S 1^{\circ}$, II do ADCT, ao valor do limite referente ao exercício imediatamente anterior, corrigido pela variação do Índice Nacional de Preços ao Consumidor Amplo (IPCA), publicado pelo Instituto Brasileiro de Geografia e Estatística (IBGE), ou de outro índice que vier a substituí-lo, para o período de doze meses, encerrado em junho do exercício anterior a que se refere a Lei Orçamentária. O $\S 5^{\circ}$ expressamente determina que é vedada a abertura de crédito suplementar ou especial que amplie o montante total autorizado de despesa primária sujeita aos limites. Rossi, Oliveira e Arantes indicam a ineficiência desta abordagem:

Ao contrário do suposto, as experiências históricas têm mostrado que a austeridade é contraproducente e gera exatamente o contrário do que busca remediar: provoca uma queda do crescimento econômico e um aumento da dívida pública. Ademais, a austeridade é seletiva, pois prejudica principalmente os mais vulneráveis (ROSSI, OLIVEIRA e ARANTES, 2017, p. 1). 
Maerk Blyth, por sua vez, argumenta ainda que, quando os serviços públicos são cortados, não são as pessoas do topo da distribuição de renda que apertam o cinto, mas aquelas da base da pirâmide social: os efeitos do corte são distribuídos injusta e insustentavelmente, uma vez que "a austeridade é, em primeiro lugar e, sobretudo, um problema político de distribuição e não um problema econômico de contabilidade" (BLYTH, 2013, p.14). ${ }^{3}$

Na mesma direção, Paul Krugman, economista laureado com o prêmio Nobel, afirmou recentemente, ao resgatar Keynes, que é no período de boom e não na depressão, a hora certa de austeridade. Segundo o autor,

isto é macroeconomia standard. Eu sempre encontro pessoas, tanto na direita, como na esquerda, que imaginam que políticas de austeridade são o que os livros dizem que deveria ser feito - e que aqueles que protestam contra a virada em direção à austeridade estão se apegando a uma espécie de posição heterodoxa radical. Mas, a verdade é que isto émainstream, os textos de economia não só justificam uma rodada inicial de estímulo pós-crise, como dizem que deveria continuar até que a economia tenha se recuperado. O que nós temos, entretanto, é uma virada radical na opinião da elite, para além de preocupação com o desemprego, em direção do foco no corte de déficits, sobretudo com corte de gastos. Por quê? Conservadores gostam de usar supostos perigos de dívida e déficit como porretes para bater no Estado de bem-estar social e justificar cortes de benefícios. (KRUGMAN, 2015, on-line).

A educação, inclusive, poderia ser um dos instrumentos deste estímulo e contribuir muito para a recuperação econômico-financeira: como aponta o comunicado no ${ }^{0}$ 75/2011, do IPEA, a cada 1,00 R\$ gasto com educação pública, 1,85 R\$ é gerado para o PIB.

A limitação das despesas primárias do Executivo federal é o que mais impacta negativamente nas políticas públicas sociais, inclusive as da educação, inviabilizando sua sobrevivência com eficácia, na medida em que provoca a compressão das despesas discricionárias e dos investimentos. Entre as despesas discricionárias estão, por exemplo, os recursos do desidratado Plano de Ações Articuladas (PAR), o livro didático (ação orçamentária 20RQ) e o funcionamento de instituições federais de ensino superior (ação 20RK). Para Rossi e Dweck (2016), os alvos do Novo Regime Fiscal são, sobretudo, a saúde e a educação:

No caso da PEC 55, a única medida relevante em matéria constitucional é a desvinculação das receitas destinadas à saúde e educação. Isto é, o Novo Regime Fiscal não precisa de emenda constitucional, o que precisa de mudança constitucional é a desvinculação de receitas para saúde e educação. Nesse sentido, a PEC do Novo Regime Fiscal é, na verdade, a PEC da desvinculação da saúde e da educação, [...],ou seja, o gasto federal real mínimo com saúde e educação será congelado no patamar de 2017 (ROSSI; DWECK, 2016, p. 2).

Mais grave é o efeito sobre o piso de gastos em educação, que foi historicamente construído desde a Constituição de 1934, mas que sempre foi atacado quando há fechamento 
político e compressão das políticas sociais (MARTINS, 2008). O jurista Miguel Reale considerava que a aplicação obrigatória da "renda resultante de impostos" é uma "inovação fundamental que se incorporou a nossa tradição" (REALE, 1984, p. 652). Há um "piso deslizante", isto é, ao longo do tempo, o valor mínimo destinado à educação cai em proporção das receitas e do PIB. Ao menos que sejam reduzidas significativamente os gastos com outras políticas de áreas também importantes, o mínimo para educação "seria de 14,4\% da receita líquida de impostos em 2026 e 11,3\% em 2036" (ROSSI, OLIVEIRA e ARANTES, 2017, p.11). Mendlovitz projetou, ainda na fase de discussão da PEC nํํㄴ 241, a evolução do piso, como pode ser visto no quadro abaixo:

\section{Quadro 1: Evolução do piso mínimo para a educação}

\begin{tabular}{|c|c|c|c|c|}
\hline Exercício & $\begin{array}{l}\text { Receita Líquida } \\
\text { de impostos } \\
\text { (RLI) }\end{array}$ & $\begin{array}{l}\text { Aplicação } \\
\text { Mínima (18\% da } \\
\text { RLI) }\end{array}$ & $\begin{array}{l}\text { Aplicação } \\
\text { Mínima pelo } \\
\text { IPCA (PEC) }\end{array}$ & $\begin{array}{l}\text { Diferença (PEC } \\
\text { e Apl. 18\%) } \\
\text { (a) (1) }\end{array}$ \\
\hline 2016 & 259,7 & 46,7 & 46,7 & $-\mathbf{( a )}$ \\
\hline 2017 & 276,7 & 49,8 & 50,2 & 0,4 \\
\hline 2018 & 296,4 & 53,3 & 52,9 & $-0,4$ \\
\hline 2019 & 315,9 & 56,9 & 55,6 & $-1,3$ \\
\hline 2020 & 336,7 & 60,6 & 58,1 & $-2,5$ \\
\hline 2021 & 359,8 & 64,8 & 60,7 & $-4,1$ \\
\hline 2022 & 384,4 & 69,2 & 63,4 & $-5,8$ \\
\hline 2023 & 411,8 & 74,1 & 66,3 & $-7,8$ \\
\hline 2024 & 442,1 & 79,6 & 69,2 & $-10,4$ \\
\hline 2025 & 475,9 & 85,7 & 72,4 & $-13,3$ \\
\hline
\end{tabular}

Fonte: MENDLOVITZ, 2016.

Ao passo que, como demonstra Castro, os interesses do capital financeiro sempre absorveram mais recursos que a área de educação, mesmo no período de expansão pós-Fundeb. Em outras palavras, a educação trava uma disputa no interior do conjunto de interesses que giram em torno do Estado brasileiro, em um quadro em que um dos maiores e mais fortes interessados atuais é o capital financeiro que, por sua vez, luta para preservar o espaço de remuneração de seus ativos, no caso, os juros nominais da dívida pública no fundo público (CASTRO, 2014). 


\section{Quadro 2: Gasto público em educação e com juros nominais (\% pib) - 2002-2010}

\begin{tabular}{|c|c|c}
\hline Ano & Gasto público em educação & Gasto públicocom juros nominais \\
\hline 2002 & 4 & 7,7 \\
\hline 2003 & 3,9 & 8,6 \\
\hline 2004 & 3,9 & 6,6 \\
\hline 2005 & 3,9 & 7,4 \\
\hline 2006 & 4,3 & 6,8 \\
\hline 2007 & 4,5 & 6,1 \\
\hline 2008 & 4,7 & 5,5 \\
\hline 2009 & 5 & 5,3 \\
\hline 2010 & 5 & 5,2 \\
\hline
\end{tabular}

Fonte: CASTRO, 2008.

Segundo dados contidos no Informativo Técnico nํ52/2018-CONOF/CD (TANNO, 2018), desde 2015 há compressão das despesas primárias no Ministério da Educação, de 208,6 em 2014 para 98,2 bilhões de reais em 2017, com queda significativa na subfunção da educação básica, de 33,7 para 26,1 bilhões de reais no mesmo período.

Todo esse cenário levaria ao que Amaral denominou de "a morte do PNE", uma vez que são congelados os recursos financeiros da educação num país que possui uma educação que aplica US\$/PPP 2.262,00 por pessoa em idade educacional, ou seja, de 0 a 24 anos, enquanto a Coréia do Sul aplica US\$/PPP 6.918,00, a Finlândia, US\$/PPP 9.891,00, a Argentina, US\$/PPP, 3.469,00, o Uruguai, US\$/PPP 2.662,00 e a Venezuela, US\$/PPP, 2.493,00. Amaral alega ainda que o poder de "destruição" da metodologia da PEC 241 (que originou a EC 95/16) promoverá mais desigualdade social, mais concentração de rendas e um "recrudescimento da vida daqueles que são mais vulneráveis, pois, se apresenta em todas as áreas sociais, como educação, saúde, previdência social e assistência social (AMARAL, 2011).

Além de todos os efeitos diretos que afetam o Plano Nacional de Educação, a vigência da EC 95 simplesmente retira o PNE da agenda política. O argumento da crise sempre pode levar alguns à tentação de relativizar ou ignorar o plano (MARTINS, 2017).

Outro efeito da EC 95 foi a indução de alterações em alguns estados, que procederam a reforma de suas constituições estaduais, estabelecendo, por mimetismo, um Novo Regime Fiscal estadual, com teto às despesas primárias. No caso do Ceará, ao menos, são excepcionalizadas as despesas com a educação. 
Quadro 3: Constituições estaduais que inseriram novo regime fiscal

\begin{tabular}{l|c|c}
\hline UF & Emenda à constituição estadual & Data \\
\hline Ceará $^{4}$ & EC 88 & $21 / 12 / 16$ \\
\hline Piauí & EC 47 & $26 / 12 / 16$ \\
\hline Mato Grosso do Sul & EC 77 & $19 / 04 / 17$ \\
\hline Goiás & EC 54 & $02 / 06 / 17$ \\
\hline Mato Grosso & EC 81 & $23 / 11 / 17$ \\
\hline
\end{tabular}

Fonte: Elaborado pelo autor

Tais medidas, para além de gerarem efeitos negativos sobre as políticas públicas, ainda acabam por realizar uma distribuição injusta e desproporcional do peso da crise entre os diferentes estratos da população. Além disso, a proposta que originou a EC 95 foi subdebatida e as condições em que se deu sua discussão não garantiram um debate democrático na essência - embora fossem formalmente respeitadas as regras (MARTINS, 2017). A discussão dessa emenda, com alteração tão radical na Constituição Federal deu-se em ambiente que não favoreceu nem um pouco o debate e a busca de melhores alternativas. Havia muitos acontecimentos simultâneos na agenda política e excesso de informação desorganizada em relação a vários temas que preocupavam e absorviam os decisores no Congresso Nacional, o que gera confusão no espaço de representação do problema (JONES, 2001). ${ }^{5}$

Como já afirmei em reflexão anterior, o ano de 2016 colocou para os legisladores uma situação de alta tensão política e circunstâncias que dispersavam sua atenção, em meio a uma sobrecarga de informações e necessidades políticas, notadamente a preparação das eleições municipais daquele ano e o controvertido e acirrado processo de impeachment da presidente da República. Isso fez com que a admissibilidade da proposta fosse aprovada sem que os parlamentares contrários à PEC sequer tivessem solicitado audiência pública da CCJC para debater sua constitucionalidade, a despeito dos elementos que indicam violação de cláusula pétrea. Isso ajuda a explicar como uma matéria desta importância teve tão poucas emendas (apenas 22), o que não favoreceu nem o debate e, tampouco, a negociação (MARTINS, 2017).

\section{Quadro 4: Cenário político e tramitação da PEC}

\begin{tabular}{ll|l|l}
\hline $\begin{array}{l}\text { Data em } \\
\mathbf{2 0 1 6}\end{array}$ & $\begin{array}{l}\text { Evento político de } \\
\text { impacto nacional }\end{array}$ & $\begin{array}{l}\text { Apreciação da PEC } \\
\mathbf{2 4 1}\end{array}$ & $\begin{array}{l}\text { Manifestações da } \\
\text { comunidade educacional }\end{array}$ \\
\hline 12 de maio & $\begin{array}{l}\text { Senado vota pela } \\
\text { admissibilidade do } \\
\text { impeachment }\end{array}$ &
\end{tabular}




\begin{tabular}{|c|c|c|c|}
\hline $\begin{array}{l}\text { Data em } \\
2016\end{array}$ & $\begin{array}{l}\text { Evento político de } \\
\text { impacto nacional }\end{array}$ & $\begin{array}{l}\text { Apreciação da PEC } \\
241\end{array}$ & $\begin{array}{l}\text { Manifestações da } \\
\text { comunidade educacional }\end{array}$ \\
\hline $\begin{array}{l}22 \text { de } \\
\text { junho }\end{array}$ & & & CNTE manifesta-se contra a PEC \\
\hline 9 de agosto & & $\begin{array}{l}\text { Admissibilidade da } \\
\text { PEC aprovada na } \\
\text { Câmara - não houve } \\
\text { audiência pública na } \\
\text { CCJC, apesar de parte } \\
\text { da comunidade jurídica } \\
\text { opinar por violação } \\
\text { de cláusula pétrea. } \\
\text { Antes da conclusão } \\
\text { do processo do } \\
\text { impeachment }\end{array}$ & \\
\hline $\begin{array}{l}17 \text { de } \\
\text { agosto }\end{array}$ & & & $\begin{array}{l}\text { Undime, Congemas e Conasems } \\
\text { manifestam-se contra a PEC }\end{array}$ \\
\hline $\begin{array}{l}24 \text { de } \\
\text { agosto }\end{array}$ & $\begin{array}{l}\text { Aprovada a LDO } \\
2017, \text { com obstrução } \\
\text { da nova oposição } \\
\text { e autorização para } \\
\text { déficit de R\$139 } \\
\text { bilhões de reais }\end{array}$ & $\begin{array}{l}1^{\text {a }} \text { audiência pública } \\
\text { na Câmara. Com o } \\
\text { ministro da Fazenda } \\
\text { e sua equipe. Sem } \\
\text { contraditório }\end{array}$ & $\begin{array}{l}\text { Ato no Congresso Nacional } \\
\text { contra a PEC } 241 / 2016 \text {, realizado } \\
\text { pelo Sinasefe, em } 24 \text { de agosto } \\
\text { de } 2016 \text {, no plenário } 2 \text { do Anexo } \\
\text { II da Câmara dos Deputados }\end{array}$ \\
\hline $\begin{array}{l}25 \text { de } \\
\text { agosto }\end{array}$ & $\begin{array}{l}\text { Oitiva de testemunhas } \\
\text { no processo do } \\
\text { impeachment no } \\
\text { Senado }\end{array}$ & & \\
\hline $\begin{array}{l}26 \text { de } \\
\text { agosto }\end{array}$ & $\begin{array}{l}\text { Início da propaganda } \\
\text { eleitoral gratuita nos } \\
\text { meios de comunicação } \\
\text { para as eleições } \\
\text { municipais de } 2016 \text {. } \\
\text { Oitiva de testemunhas } \\
\text { no processo do } \\
\text { impeachment no } \\
\text { Senado }\end{array}$ & & \\
\hline $\begin{array}{l}29 \text { de } \\
\text { agosto }\end{array}$ & $\begin{array}{l}\text { Manchete política } \\
\text { do Estadão:"Senado } \\
\text { recebe Dilma hoje, em } \\
\text { clima de tensão" }\end{array}$ & $\begin{array}{l}2^{a} \text { audiência pública } \\
\text { na Câmara. Com o } \\
\text { ministro da Fazenda } \\
\text { e sua equipe. Posições } \\
\text { favoráveis (ministério } \\
\text { da Saúde e economista } \\
\text { Bernardo Appy) e } \\
\text { contrárias (secretarias } \\
\text { municipais de saúde e } \\
\text { educação) }\end{array}$ & \\
\hline
\end{tabular}




\begin{tabular}{|c|c|c|c|}
\hline $\begin{array}{l}\text { Data em } \\
2016\end{array}$ & $\begin{array}{l}\text { Evento político de } \\
\text { impacto nacional }\end{array}$ & $\begin{array}{l}\text { Apreciação da PEC } \\
241\end{array}$ & $\begin{array}{l}\text { Manifestações da } \\
\text { comunidade educacional }\end{array}$ \\
\hline $\begin{array}{l}31 \text { de } \\
\text { agosto }\end{array}$ & $\begin{array}{l}\text { Concluído o processo } \\
\text { de impeachment }\end{array}$ & $\begin{array}{l}3^{\text {a }} \text { audiência pública na } \\
\text { Câmara. Economistas } \\
\text { Raul Velloso e Samuel } \\
\text { Pessoa, favoráveis à } \\
\text { PEC. Sem contraditório }\end{array}$ & \\
\hline $\begin{array}{l}12 \text { de } \\
\text { setembro }\end{array}$ & $\begin{array}{l}\text { Aprovada a cassação } \\
\text { do então presidente } \\
\text { da Câmara, Eduardo } \\
\text { Cunha. }\end{array}$ & $\begin{array}{l}4^{\text {a }} \text { (e última) audiência } \\
\text { pública na Câmara. } \\
\text { Com os presentes } \\
\text { do IPEA e Febraban, } \\
\text { a favor da PEC e a } \\
\text { auditora fiscal Maria } \\
\text { Lúcia Fatorelli, } \\
\text { contrária à PEC. }\end{array}$ & \\
\hline
\end{tabular}

Campanha Nacional pelo Direito à Educação, entregou na 71ํㅡㄹ Assembleia Geral da ONU,

18 de

setembro dossiê à EducationCommission sobre, entre outros temas, a PEC 241/2016, que na avaliação da entidade colocava em risco a garantia do direito humano à educação no Brasil

Fórum Nacional de Educação lançou a $44^{a}$ Nota Pública - PEC 241 inviabiliza as metas do PNE

setembro

Fim da propaganda eleitoral gratuita para

29 de as eleiçõos municipais-

setembro que perdurou em todo período de debate da PEC na Comissão Especial na Câmara

02 de Primeiro turno das outubro eleições municipais

08 de outubro

Consed lançou nota em que “... entende a necessidade da adoção de medidas de ajuste, mas alerta para a necessidade de tratar a Educação de maneira diferenciada para ser prioridade frente aos desafios para execução do PNE

\begin{tabular}{l|l}
$\begin{array}{l}25 \text { de } \\
\text { outubro }\end{array}$ & \\
\hline $\begin{array}{l}\text { 30 de } \\
\text { outubro }\end{array}$ & $\begin{array}{l}2^{\circ} \text { turno das eleições } \\
\text { municipais }\end{array}$
\end{tabular}

votação em segundo turno da PEC 241 na Câmara dos Deputados 


\begin{tabular}{|l|l|l|l}
\hline $\begin{array}{l}\text { Data em } \\
\mathbf{2 0 1 6}\end{array}$ & $\begin{array}{l}\text { Evento político de } \\
\text { impacto nacional }\end{array}$ & $\begin{array}{l}\text { Apreciação da PEC } \\
\mathbf{2 4 1}\end{array}$ & $\begin{array}{l}\text { Manifestações da } \\
\text { comunidade educacional }\end{array}$ \\
\hline & $\begin{array}{l}\text { Manchetes: } \\
\text {-portal uol: Executivo } \\
\text { da Odebrecht delata } \\
\text { cúpula do PMDB e } \\
\text { cita propinas de mais } \\
\text { de R\$22 mi, diz JN..- }\end{array}$ & & \\
\hline $\begin{array}{l}\text { 09 de } \\
\text { dezembro }\end{array}$ & $\begin{array}{l}\text { JB-Primeira das 77 } \\
\text { delações da Odebrecht } \\
\text { atinge Temer, cúpula } \\
\text { do PMDB e aliados }\end{array}$ & & \\
\hline $\begin{array}{l}13 \text { de } \\
\text { dezembro }\end{array}$ & $\begin{array}{l}\text { Aprovação da PEC no } \\
\text { 15 de } \\
\text { dezembro }\end{array}$ & Senado & \\
\hline
\end{tabular}

Desde o advento da Emenda Constitucional nº 14/96, não restam dúvidas de que a vinculação dos recursos à educação não é mera exceção ao princípio da não-afetação do direito financeiro, mas constitui princípio autônomo, trazido do direito educacional para a Carta Magna, expressamente previsto (art.34, VII, “ $\mathrm{e}^{\prime \prime}, \mathrm{CF}$ ) e com status de princípio sensível cuja violação implica a mais grave sanção no Direito Constitucional: a decretação de intervenção federal (MARTINS, 2017; PINTO, 2017). Se a própria Federação, como forma de Estado, é objeto (art. 60, $4^{\circ}$, I, CF) de cláusula pétrea, sanção da gravidade da intervenção federal indica que a norma que a fundamentou não pode ter outra natureza.

Finalmente, a EC 95, ao estrangular os recursos educacionais, impede que se lide com o investimento no aluno. $\mathrm{O}$ valor aplicado por aluno dá um retrato mais preciso do esforço do País para financiar sua educação. Frequentemente, apresenta-se, de maneira isolada e descontextualizada, o percentual do PIB, em comparação com outros países, sem levar em consideração, entre outros aspectos como: o tamanho do PIB; a população que deve ser atendida - o que exige ainda esforço de inclusão de 600 mil crianças de 6 a 14 anos de idade e mais 900 mil adolescentes de 15 a 17 anos, que se encontram fora da escola; os desafios de infraestrutura; a adoção do tempo integral e a atratividade da carreira docente. 
Quadro 5: Gasto por aluno de nível primário nos países selecionados em $2014^{6}$

\begin{tabular}{l|c}
\hline PAÍS & GASTO ALUNO -NÍVEL PRIMÁRIO \\
\hline Reino Unido & 11.367 \\
\hline Finlândia & 8.812 \\
\hline Média Ocde & 8.733 \\
\hline Alemanha & 8.546 \\
\hline Coreia & 9.656 \\
\hline Irlanda & 8.007 \\
\hline Portuga & 6.474 \\
\hline Chile & 4.321 \\
\hline Brasil & 3.799 \\
\hline
\end{tabular}

Fonte: OCDE - Education at a Glance - 2017, pg 177.

A EC 95 tem por objeto a recuperação econômica, mas infelizmente desconsidera a importância da educação como indutora de outras políticas públicas, como multiplicador do PIB e como fator de aumento da produtividade - que será necessária num mercado global cada vez mais complexo e com uma população economicamente ativa em menor número - que pode chegar com qualificação mais baixa do que a desejável em um momento em que a população de idosos será maior.

Ainda que haja a exclusão da complementação da União ao Fundeb do teto, as autoridades da área econômica presentes à audiência pública da Comissão Especial que discute a PEC no 15 de 2015, referente ao Fundeb permanente, deixaram clara a posição de não utilizar a possibilidade de qualquer aumento deste recurso, que já se revela insuficiente.

O problema principal da EC 95 é menos normativo que cultural - propõe uma cultura de austeridade em sacrifício das políticas educacionais e contra o espírito da Constituição Cidadã, que completa trinta anos.

Recebido em: 28/06/2018 e aprovado em: 17/08/2018 


\section{Notas}

1 Despesa primária é a despesa total menos a despesa financeira (amortização de dívidas, juros passivos, concessão de empréstimos). Assim, um dos itens que mais impacta na dívida pública - os juros - não é disciplinado, é beneficiado por vinculações a seu pagamento e não conhece limites.

2 Para 2017, o limite foi equivalente à despesa primária paga no exercício de 2016, incluídos os restos a pagar pagos e demais operações que afetaram o resultado primário, corrigida em 7,2\% (sete inteiros e dois décimos por cento).

3 Tradução livre feita pelo autor. No original: "Austerity is first, and fore most, a political problem of distribution, and not an economic problem of accountancy.

4 Uma observação pertinente no caso do novo regime fiscal do Ceará é a de que as despesas da educação não são incluídas na base de cálculo para limitação.

5 O suprimento ininterrupto de informações que competem pela atenção do ator causa uma sobrecarga de informação (BAWDEN e ROBINSON, 2008). Pode haver a manipulação da atenção, com inundação de informações sobre outro tema que desvia a atenção do assunto inicial, criando-se uma distração (PERSSON,2012).

6 Para este cálculo foram considerados dólares equivalentes, convertidos por paridade de poder aquisitivo ou paridade de poder de compra (PPP).

7 Somente instituições públicas.

\section{Referências}

AMARAL, Nelson Cardoso. PEC 241/55: a "morte" do PNE (2014-2024) e o poder de diminuição dos recursos educacionais. Revista Brasileira de Política e Administração da Educação, ANPAE: S.l., v. 32, n. 3, p. 653 - 673, dezembro de 2016.

BAWDEN, David; ROBINSON, Lyn. The dark side of information: overload, anxiety and other paradoxes and pathologies. Journal of Information Science, Reino Unido, v. 35, n.2, p. 180-191, novembro de 2008 .

BLYTH, Maerk. Austerity: the history of a dangerous idea. New York: Oxford University Press, 2013.

CASTRO, Jorge Abrahão de. Dilemas para o Financiamento da Educação. In: BRASIL. O Sistema Nacional de Educação: diversos olhares 80 anos após o Manifesto. MEC/SASE: Brasília, 2014.

INEP. Relatório do $2^{0}$ ciclo de monitoramento das metas do Plano Nacional de Educação (2018). Brasília: MEC/Inep, 2018.

IPEA. Comunicado no 75 de 03 de fevereiro de 2011, referente aos de gastos com a política sócial, alavanca para o crescimento com distribuição de renda. Brasília: MEC/Inep, 2011.

JONES, Bryan D. Politics and the Architecture of Choice: bounded rationality and governance. The University of Chicago Press: Chicago and London, 2001.

KRUGMAN, Paul. The case for cuts was a lie. Why does Britain still believe it? The austerity delusion. The Guardian 29 de abril de 2015. 
MARTINS, Paulo de Sena. O financiamento da educação e a constituição de 1988: a vinculação de recursos à manutenção e ao desenvolvimento do ensino. p. P. 449-461. In: ARAÚJO et al. (Orgs.) Ensaios sobre impactos da Constituição de 1988 na sociedade brasileira. Brasília: Câmara dos Deputados/Consultoria Legislativa, 2008. Volume 1.

Impactos da Emenda Constitucional no 95 no financiamento da Educação. In: JESUS, Wellington Ferreira de. O Financiamento da Educação Básica no Brasil em tempos de golpe parlamentar e da EC 95/2016: antigos desafios e novas possibilidades. Uberlândia: Culturatrix, 2017.

MENDLOVITZ, Marcos. Análise dos efeitos da PEC nํำ 241 sobre a Manutenção e Desenvolvimento do Ensino. Informativo Técnico n⿳o 11/2016. CONOF/CD: Brasília, 2016.

PERSSON, Petra. Attention, Manipulation and Information Overload. Behavioural Public Policy, Cambridge University Press: Reino Unido, v. 2, n. 1, p 78-106, julho de 2012.

PINTO, Élida Graziane. Financiamento dos Direitos à Saúde e à Educação: uma perspectiva constitucional. Belo Horizonte: Fórum, 2017.

REALE, Miguel. Educação e Cultura na Constituição Brasileira. Revista Brasileira de Estudos Pedagógicos, Brasília, v. 65, set./nov.1984.

ROSSI, Pedro; DWECK, Esther. Impactos do Novo Regime Fiscal na saúde e educação. Cad. Saúde Pública, Rio de Janeiro: Fiocruz, v. 3, n. 12, p. 1-5, janeiro de 2016.

ROSSI, Pedro; OLIVEIRA, Ana Luiza Matos de; ARANTES, Flávio. Austeridade e impactos no Brasil: ajuste fiscal, teto de gastos e o financiamento da educação pública. Análise, São Paulo: Friedrich Ebert Stiftung $\mathrm{n}^{\mathbf{0}} 33$, p. 1-19, setembro de 2017.

TANNO, Cláudio. Informativo Técnico nº 52/2018. CONOF/CD: Brasília, 2018. 